\title{
Michael Handelsman: lector de Benjamín Carrión
}

Michael Handelsman: reader of Benjamín Carrión

\section{Raúl Serrano Sánchez}

Universidad Andina Simón Bolívar, Sede Ecuador, Quito

DOI: https://doi.org/10.32719/13900102.2019.45.6

Fecha de recepción: 17 enero 2019

Fecha de aceptación: 29 marzo 2019 


\section{RESUMEN}

Este texto examina las aproximaciones y perspectivas críticas desarrolladas por el académico norteamericano Michael Handelsman respecto a la obra y el pensamiento del crítico y ensayista ecuatoriano Benjamín Carrión, uno de los hermeneutas más connotados de la denominada Generación del 30 y el Grupo de Guayaquil en Ecuador durante el siglo pasado. Handelsman ha hecho un amplio y exhaustivo examen de la obra de Carrión, que incluye su vasta y compleja correspondencia, sin dejar de lado de señalar los aciertos y de precisar los señalamientos críticos que esa obra, como el pensamiento y el accionar político de Carrión, demandan.

Palabras ClaVe: Benjamín Carrión, Michael Handelsman, crítica, ensayo, Ecuador, literatura, cultura, ecuatorianistas.

\section{ABSTRACT}

This text examines the critical approaches and perspectives developed by American scholar Michael Handelsman with respect to the works and thought of Ecuadorian critic and essayist Benjamín Carrión, one of the most outstanding hermeneutists in the Generation of the Thirties and the Guayaquil Group in Ecuador during the past century. Handelsman has performed a broad and exhaustive study of Carrión's works, including his vast and complex correspondence, without leaving aside the correct critical assumptions and statements that said works, as Carrión's thought and political action, demand. KEYwords: Benjamín Carrión, Michael Handelsman, critique, essay, Ecuador, Literature, culture, Ecuadorianists.

Michael Handelsman (1948) es un ecuatorianista de vocación más que comprobada. Su pasión por la literatura y la cultura del Ecuador, de manera particular, y por la de América Latina en general, se evidencia en su ya vasta bibliografía, en la que hay estudios que dan cuenta, de manera pionera, lo que es la prosa de las escritoras ecuatorianas desde inicios del siglo XX, hasta lo que es el aporte del modernismo y sus revistas. Amplio e intenso trabajo de archivo de ese período en Ecuador, pasando por los diversos estudios que le ha dedicado a los autores del canon de la literatura nacional como Juan León Mera, Medardo Ángel Silva, José de la Cuadra, Alfredo Pareja Diezcanseco, Demetrio Aguilera Malta, Jorge Icaza, Pablo Palacio, Adalberto Ortiz, Nelson Estupiñán Basss, Ángel F. Rojas, hasta llegar a los debates de este período de transiciones, un terreno poroso, que es la modernidad; período en el que Handelsman ha puesto, al servicio de su ejercicio crítico, una serie de recursos y estrategias tomadas o expoliadas de lo que son los estudios culturales y la crítica alternativa. Acopio de aquellos nuevos enfoques y formas de examinar la literatura (poniendo en 
tensión los giros decoloniales y los estudios inter y pluriculturales), como lo hizo con su aproximación a la literatura afro, y que sin duda -esto siempre será lo más interesante de sus trabajos- son una invitación al diálogo, por cierto nunca complaciente, sino a aquel que hace de la discusión una forma, la más brillante, para llegar a deconstruir aquello sobre lo que más que certezas, lo que subyacen son dudas y, sobre todo, sospechas.

De ahí que la crítica de y en Handelsman sea una continua provocación. Y provocación no quiere decir asumir posturas fundamentalistas, o pretender convertirse en quien se sabe el hacedor de verdades que busca transformar en ley o en una especie de catecismo a las que otros deben sumarse con la ceguera del que adscribe a sectas en las que nadie tiene derecho a disentir. La suya es una crítica que está en diálogo constante con la tradición, pero que muestra sus giros de ruptura a partir de que esa tradición siempre está siendo sometida a nuevos ajustes, a puntualizaciones en las que el instrumental teórico nunca llega a perturbar ni a convertir el lenguaje del crítico en un metalenguaje que termina por ser reo de cierto academicismo acartonado, del que por lo general ni los habitúes o los exiliados de la academia quieren saber algo, mucho menos ese lector que está en la otra orilla, que quiere tener nuevas pistas que le permitan entrar a desmontar aquellos textos sobre los que en apariencia ya se ha dicho casi todo. En Handelsman se cumple aquello que señala Octavio Paz: "La crítica opera por negaciones y por asociaciones: define, aísla y, después, relaciona" $(1988,44)$.

Quizás ahí resida, en esas operaciones, la condición de ser un crítico postmoderno. En esa posibilidad de descubrirse un sujeto en continúa transición; además, un sujeto que pone en crisis la modernidad y esa postmodernidad en tanto y en cuanto que sus lecturas de la tradición, como de lo contemporáneo o actual, participa de una reticencia propia de quien tiene el olfato y su detector de crítico debidamente afilados. Parte también de ese ejercicio crítico de Handelsman tiene que ver con la idea de celebrar e incluso evidenciar con su escritura y lecturas la posibilidad de desplazamiento al asumir, desde su matriz cultural e intelectual (por tanto política), diversas líneas o componentes para su desciframientos como lector. Hecho que lo podemos evidenciar en la pluralidad de autores y textos que a lo largo de los años ha abordado con una intensidad que nunca ha renunciado al rigor ni tampoco a algo que es clave en sus ensayos: la senci- 
llez, que como sabemos, es una de las mayores complejidades a conseguir para cualquier autor o autora en este mundo.

Decir que Michael Handelsman es un conocedor de la literatura ecuatoriana tal vez sea una ligereza. Creo que es uno de los mayores estudiosos de esta literatura a la que él con sus hallazgos y aproximaciones a propios y extraños nos ha terminado por arrancar más de un asombro. Por ejemplo, cuando publicó su estudio Amazonas y artistas (1978), a todos nos obligó, dentro de la comarca excluyente y masculinizante, a mirar una tradición y escritura, la de las autoras del Ecuador, de la que se habían dicho cosas a medias o muy mezquinas, muchas mezcladas con esas visiones normalizadas de un machismo que también era parte de las limitantes formas de entender nuestro devenir político y cultural.

Como parte de sus atenciones de estudioso de la literatura ecuatoriana, hay que subrayar que de todos los autores del siglo XX a los que Handelsman le ha brindado su atención de manera particular, como crítico y analista, es la figura de Benjamín Carrión (Loja, 1897-Quito, 1979), uno de los ensayistas e intelectuales más polémicos, elogiados por unos y denostado por otros, y al que muy bien cabe definir, usando las palabras con las que el mismo Carrión habló del peruano Mariátegui, como "el precursor, el anticipador, el suscitador”. Cuenta Handelsman que en 1984 concibió el proyecto de examinar la obra, trayectoria, teorías y personalidad de Carrión, "convencido de la necesidad de contrarrestar el silencio y la indiferencia crítica (la ignorancia) que amenazan con negarle al Maestro ecuatoriano su justo lugar entre otros intelectuales combatientes de prominencia de América Latina" (1989, 10). Hay que destacar que Carrión es el gran hermeneuta y crítico de lo que él definió como la Generación del 30 , en la que destacan los novelistas del indigenismo como Icaza y del realismo abierto como Palacio, del realismo integral como Humberto Salvador y de lo real-mítico como José de la Cuadra y Aguilera Malta. Sin duda las valoraciones de Carrión, lúcidas y que responden, como bien anota Handelsman, a su método impresionista (es el que forjó para su época), aún no dejan de sorprender, pues su vigencia es incuestionable dado que el lector, el crítico agudo, intuitivo de ese período, que supo apostar por esa literatura de vanguardia y fundacional en su hora y encrucijada, posterior a la publicación del indispensable estudio El nuevo relato ecuatoriano (1958), fue desplazado por el suscitador, el intelectual comprometido con 
causas políticas y proyectos culturales que demandaron de su tiempo y concentración.

Resultado de estas indagaciones que le llevó varios años, es la edición y estudio crítico de Cartas al Ecuador (1943), que publicó el Banco Central del Ecuador y la Corporación Editora Nacional en 1988, que también incluye la serie Nuevas cartas al Ecuador que Carrión dio a conocer hacia finales de la década del 50 en la célebre revista política La Calle, que dirigían los escritores Pedro Jorge Vera y Alejandro Carrión, su sobrino, que luego de su repentina conversión ideológica se erguiría en uno de sus más acérrimos y militantes detractores. Al año siguiente, con Editorial El Conejo de Quito, aparece En torno al verdadero Benjamín Carrión (1989). Aunque antes, en 1984, en la revista Cuadernos Americanos, publicó el ensayo "Benjamín Carrión y su concepto de la identidad nacional ante los peligros de la penetración cultural”, del que incluyó una versión acotada en su libro Incursiones en el mundo literario del Ecuador (1987); ensayo que luego formará parte de En torno al verdadero Benjamín Carrión. Cerrando su plan de investigaciones, en 1991, con Editorial Planeta, sale Ideario de Benjamín Carrión, que incluye su ensayo sobre uno -Handelsmann lo reitera- de los libros más logrados y polémicos del lojano, Atahuallpa, publicado originalmente en México en 1934, y del que se han hecho varias reediciones. Ese artículo se titula "Atahuallpa y Benjamín Carrión ante la historia nacional del Ecuador”.

A estos títulos hay que sumar el ensayo "Benjamín Carrión entre la modernidad y la postmodernidad", que Handelsman publica en el anuario Re/incidencias del Centro Cultural Benjamín Carrión de Quito en 2005; Benjamin Carrión: Pensamiento Fundamental (Quito, Campaña Nacional Eugenio Espejo Por el Libro y la Lectura/Universidad Andina Simón Bolívar, Sede Ecuador/Corporación Editora Nacional, 2007) y "Visiones del mestizaje en Indología de José Vasconcelos y Atahuallpa de Benjamín Carrión", incluido en el volumen De Atahuallpa a Cuaubtémoc: Los nacionalismos culturales de Benjamín Carrión y José Vasconcelos, coeditado con el académico Juan Carlos Grijalva en 2014. Ensayo que como bien advierte Handelsman "es, en parte, una adaptación de algunas ideas expresadas" en el texto que cierra Ideario de Benjamin Carrión (1991, 135-48).

Respecto al primero y al segundo de estos estudios, Handelsman comenta: "Cartas al Ecuador, ensayos seminales en que Carrión había intentado definir 'la ecuatorianidad', fue un intento de rescatar y hacer 
circular unos materiales fundamentales del pensamiento ecuatoriano del siglo XX. Luego, con En torno al verdadero Benjamín Carrión, procuramos analizar varios aspectos de la naturaleza polémica y controvertible de Carrión, el escritor y el hombre" (1991, 12). Con relación al tercero, anota: "En vez de ofrecer una antología de ciertos ensayos completos de Carrión, hemos optado por identificar quince temas que han sido constantes en su vasta obra, y mediante un compendio de selecciones y extractos pertinente a cada uno de los quince temas, hemos querido presentarle al lector un corpus crítico-bibliográfico diverso y extenso del ideario de Carrión" (12-3). Este libro, a más de la selección de fragmentos divididos en "cuatro áreas principales, a saber: la justicia social, la cultura nacional, la crítica literaria (y sobre todo, las funciones del arte y del intelectual frente a la sociedad) y la Segunda Independencia de América Latina” (13), incluye una serie de valoraciones críticas en las que Handelsman con soltura y lucidez va contextualizando lo que dentro del ideario carrioniano significa e implican los conceptos o apreciaciones que el maestro ha trazado respecto a los temas de los que reflexiona en cada uno de los fragmentos escogidos.

Estas "áreas" dan cuenta, de manera vital de los motivos o fundamentos temáticos que cimentan el amplio, polémico y contradictorio "ideario" carrioniano, que Handelsman, como pocos ha revisado de uno a otro extremo. El examen que el crítico nos ofrece de la obra de Carrión no es parcial, es exhaustivo. Lo que prima en estas indagaciones y reflexiones (Handelsman años después lo reiterará) es superar esos apasionamientos que llevó a unos a elogiar de manera casi que fundamentalista y dogmática la figura de Carrión, el hombre de acción, el militante del progresismo, pasando por alto sus textos claves; y a otros, considerando sus ensayos vitales, a desarrollar lecturas en las que el enfoque crítico se veía desvirtuado por ese afán de poner en evidencia, sin las debidas contextualizaciones y argumentaciones, los crasos errores o equívocos de Carrión, a quien se le pedía o exigía (aún sucede) aquello que el pensamiento y la obra del maestro no nos podía ni puede dar. De ahí que al volver a Carrión con motivo de los 25 años de su desaparición física, Handelsman anote lo siguiente: “quizás los ánimos de hoy estén mejor preparados para tratar el tema Carrión sin recurrir a posiciones y a tonos tan marcadamente personales o defensivos" $(2005,465)$. 
De todos los textos que Handelsman le dedica al lojano, sin duda que En torno al verdadero Benjamín Carrión y el Ideario resultan reveladores y complementarios.

El primero se compone de cinco ensayos que teniendo su independencia, incluso dos se publicaron en Cuadernos Americanos (revista en la que Carrión colaboró de manera asidua dada su amistad con su director, el mexicano Jesús Silva Herzog), se ensamblan perfectamente. Los títulos de cada uno de estos capítulos nos participan de lo que son sus argumentos de fondo: "I. la figura polémica y contradictoria de Benjamín Carrión; II. Hombre de América; III. Las múltiples imágenes de Carrión: su correspondencia como espejo prismático; IV. Benjamín Carrión y su concepto de la identidad nacional ecuatoriana; V. La Casa de la Cultura Ecuatoriana: reflexiones de Benjamín Carrión”.

El examen que Handelsman propone de estos aspectos del pensamiento y el accionar de Carrión, parte por considerar dos de los ensayos más esclarecedores que se han escrito en el Ecuador sobre el autor de Mapa de América. El uno es el de Alejandro Moreano: "Benjamín Carrión: el desarrollo y la crisis del pensamiento democrático" (1980, 2334); el otro de Fernando Tinajero: "La fortuna de una idea desdichada", recogido en su libro Aproximaciones y distancias (1986, 137-54). Si bien los apuntes de Moreano se proponen ubicar las filiaciones y el sentido del pensamiento de Carrión, señalando su base liberal-burguesa, así como establecer las limitaciones y el carácter contradictorio, por tanto de su obra y pensamiento al proponerse como los de un militante de la izquierda, el de Tinajero persigue desmitificar los desaciertos (por contradictorios) respecto a las postulados teóricos que Carrión maneja sobre su teoría de la cultura, la nación, lo identitario y lo político.

Ambos enfoques pertenecen a críticos marxistas, que en el caso de Tinajero, años después llegaría a reconocer, desde el ejercicio de la autocrítica, que en su revisión de los postulados carrionanos (El siglo de Carrión, 2016) se le fue la mano al momento de poner en evidencia las paradojas de quien sin duda había desarrollado una visión de la cultura del país, desde lo que era su utopismo eurocéntrico y su acendrado arielismo. Visiones que como bien advierte Handelsman, en muchos de los casos obedecen al nivel intuitivo de quien más que un teórico en términos convencionales, era un escritor (un literato) que ajeno a cualquier método se había propuesto diseñar (quizás forjar el suyo) con pasión, como lo advirtió en su momento 
al concebir su "plan del Ecuador” (Serrano Sánchez 2010). Esto es trazar una serie de miradas y coordenadas que muchas de las veces están atravesadas por tensiones que le imponían las coyunturas, como sucedió en los dramáticos años posteriores a la firma del cuestionable Protocolo de Río de Janeiro de 1942 y el tiempo nublado de la dictadura civil del plutócrata Arroyo del Río.

Hace bien Handelsman en recordarnos que las visiones, más que las concepciones teóricas de Carrión, responden a las contradicciones propias de un creador antes que a las de un teórico que siempre fue un socialista utópico y no un socialista distópico. Un Carrión que como buen heredero de la ilustración y el romanticismo europeo, pensó la nación y la cultura de esa nación desde sus lecturas cargadas de pasión y entusiasmo de “precursor y suscitador" al que el pensamiento y la obra de Martí como la de Vasconcelos (el primer Vasconcelos) terminan por marcar, así como el pensamiento del uruguayo José Enrique Rodó. De ahí, como bien lo precisa Handelsman, que Carrión no sea afín a seguir o aplicar algún método científico, como en su hora lo hizo su admirado (en un segundo momento) José Carlos Mariátegui, con 7 ensayos de interpretación de la realidad peruana (1928), que obedecen a una aplicación de todo lo que el aparataje del marxismo le dictaba. Carrión -quizás ese es el equívoco de ciertos críticos- hay que dejarlo claro, no era ni quiso ser un marxista. Si militó en el Partido Socialista Ecuatoriano, eso respondió a lo que era su impulso de intelectual que estaba convencido, desde sus visiones e influencias del arielismo, que desde la cultura o interfiriendo todo lo que esta ponía en tensión y crisis, podía llevar adelante una serie de acciones de carácter práctico que más que ser revolucionarias, tenían una carga democrática-liberal-burguesa. Fue así como Carrión, dentro de una coyuntura histórica en la que se da la revuelta de La Gloriosa, que sacó del poder a Arroyo del Río en mayo de 1944, logró materializar uno de sus más anhelados proyectos: la creación de la Casa de la Cultura Ecuatoriana. Uno de los escasos logros de la revuelta de Mayo de 1944, y una -para Carrión- de sus mayores realizaciones y a la que siempre defendió con celo de amante intransigente.

El proyecto de la Casa (consagración de su teoría cargada, como bien señala Handelsman, de idealismo y abstracción respecto a la cultura), fue para Carrión una de las obsesiones que empezó a configurar a partir de su primer viaje a México en la década del 30, de los contactos con el pen- 
samiento del primer Vasconcelos, porque hay un segundo del que Carrión se distancia cuando el mexicano adscribe a posturas políticas contrarias a las que había profesado inicialmente. Handelsman observa, respecto a lo que anhelaba Carrión con su noción de cultura para el Ecuador: "En realidad, la deseada armonía que Carrión buscaba en la cultura pertenecía a un proceso de mestización artificial que ocultaba la naturaleza multiétnica y heterogénea del país" (1991, 126).

Pero quien nutre las obsesiones del lojano respecto al plan de una Casa de la Cultura, es su comadre Gabriela Mistral que colaboró en la Secretaría de Educación con Vasconcelos cuando este la invitó a ser parte de ese México que estaba trastornado por los efectos de la revolución. Mistral, a quien Carrión le dedica uno de sus santorales (Carrión 1956), tratándola siempre como una santa laica y no como la mujer compleja, que desde la noción burguesa del pecado atentó por medio de su escritura contra el orden político y sexual de su entorno. La poeta chilena es quien en los diálogos y cartas que se cruzaron por esos años le da algunas claves de lo que luego será el programa, el proyecto cultural del ecuatoriano. Proyecto al que él le puso, no se puede dejar de reconocer esto, lo suyo, sus particularidades. Handelsman, en su evaluación de lo que implicó este proyecto mayor de la Casa, apunta:

\begin{abstract}
A pesar de las limitaciones de su concepto de la cultura y de la casa a la que pertenecía, no hemos de negarle a Carrión sus méritos. Curiosamente, mientras la orientación arielista de Carrión se descarrila frente a un Ecuador pluralista que ahora busca su unidad dentro de una diversidad a menudo conflictiva, este mismo arielismo no es del todo despreciable ya que puede ser que contenga algunas semillas que podrán dar frutos insospechados en un futuro no tan distante (127).
\end{abstract}

La pregunta que Handelsman nos propone, una vez concluida la lectura de su totalizador En torno al verdadero Benjamín Carrión, es dónde está, dónde habita el verdadero Carrión. Qué lo hace un contemporáneo nuestro. Qué propone aún su palabra, su pensamiento cuyos mayores hallazgos salen desde su poderosa y desconcertante intuición de crítico y lector avizor; esa condición que como nos lo recuerda Juan Carlos Onetti, es la que en el creador define casi todo.

¿Siempre hubo más de un Benjamín Carrión? Aquel que, a la luz del examen que Handelsman nos ofrece con pertinencia y sagacidad de su 
intensa correspondencia, es el hombre, el sujeto que de pronto reivindica a Maquiavelo en desmedro de Rodó y de su maestro Próspero. Dónde está ese Carrión que habla de su país, de su literatura y cultura con tal pasión que todos nos detenemos a pensar, si en verdad habitaba esta "nación pequeña" o era uno de esos personajes que su amigo y discípulo Pablo Palacio inventó en esas historias tan despiadadas, hilarantes y alucinadas en las que reconocerlo, reconocernos, es como haber encontrado parte de ese "bolo de lodo suburbano" que Palacio echó a rodar para que aquellos que le encuentren carne de su carne se tapen las narices.

¿Dónde está, dónde se quedó ese verdadero Benjamín Carrión? Ese "gran señor de la nación pequeña" al que celebró y cantó uno de sus grandes camaradas y cómplices, Jorgenrique Adoum, en un texto que se ha citado en tantas y poco oportunas ocasiones.

Mientras no lo tengamos muy claro (esperemos que siempre sea así), volver a sus ensayos siempre será algo así como un desafío del que estos lúcidos y reveladores desciframientos de Michael Handelsman jamás podrán, ni deben, quedar de lado. *

\section{Bibliografía}

Carrión, Benjamín. 1956. Santa Gabriela Mistral. Quito: Casa de la Cultura Ecuatoriana.

- 1958. El nuevo relato ecuatoriano. Quito: Casa de la Cultura Ecuatoriana.

Grijalva, Juan Carlos, y Michael Handelsman, ed. 2014. De Atahuallpa a Cuauhtémoc: los nacionalismos culturales de Benjamín Carrión y José Vasconcelos. Pittsburgh: Instituto Internacional de Literatura Iberoamericana/Museo de la Ciudad de Quito.

Handelsman, Michael. 1991. Ideario de Benjamin Carrión. Quito: Planeta.

—. 2005. "Benjamín Carrión entre la modernidad y la posmodernidad". Re/incidencias (Centro Cultural Benjamín Carrión, Quito), n. ${ }^{\circ} 3$ (diciembre).

Moreano, Alejandro. 1980. "Benjamín Carrión: el desarrollo y la crisis del pensamiento democrático". Argumentos (Quito) n. ${ }^{\circ} \mathrm{l}$ (agosto): 23-34.

Paz, Octavio. 1988 [1967]. Corriente alterna. México: Siglo XXI Editores.

Serrano Sánchez, Raúl. 2010. "Benjamín Carrión: metáforas de la memoria”. En Plan del Ecuador. Quito: Ministerio de Educación.

Tinajero, Fernando. 1986. Aproximaciones y distancias. Quito: Planeta.

—. 2016. El siglo de Carrión. Quito: Casa de la Cultura Ecuatoriana. 